\title{
Laparoscopic-assisted Esophageal Bypass for T4b Esophageal Tumor as a Bridge to Definitive Therapy
}

\author{
SPYRIDON DAVAKIS ${ }^{1}$, ATHANASIOS SYLLAIOS $^{1}$, EFSTRATIA MPAILI $^{1}$, \\ THEODOROS LIAKAKOS ${ }^{1}$ and ALEXANDROS CHARALABOPOULOS ${ }^{1,2}$ \\ ${ }^{1}$ First Department of Surgery, Upper Gastrointestinal and General Surgery Unit, \\ Laiko General Hospital, National and Kapodistrian University of Athens, Athens, Greece; \\ ${ }^{2}$ Regional Oesophago-Gastric Cancer Centre, Department of Upper Gastrointestinal Surgery, \\ Broomfield Hospital, Mid Essex Hospital Services NHS Trust, Chelmsford, U.K.
}

\begin{abstract}
Background/Aim: Esophagobronchial fistula is a common complication of advanced esophageal cancer, related to respiratory distress and mortality. Esophageal bypass has been successfully utilized for palliation, as bridging to definitive chemoradiotherapy. The aim of this study is to present an extremely difficult case of a mid-esophageal squamous cell carcinoma complicated with aerodigestive fistula that was treated using $3 D$ laparoscopic-assisted esophageal bypass with curative intent. Case Report: A 49year-old female patient presented with T4b esophagealsquamous cell carcinoma and esophagobronchial fistula. Laparoscopic-assisted V-shaped retrosternal esophageal bypass using a gastric conduit was started, which was converted to open surgery due to respiratory distress. The patient was able to undergo chemoradiotherapy treatment. Conclusion: 3D laparoscopic-assisted esophageal bypass can be a safe and feasible approach in patients with advanced midesophageal squamous cell carcinoma and esophagobroncial fistula. Additionally to the advantages of laparoscopic surgery, this operation permits oral feeding, and can be used with possible curative intent in patients with adequate response to chemoradiotherapy.
\end{abstract}

Esophageal cancer is the eighth most common malignancy and the sixth leading cause of cancer mortality worldwide

This article is freely accessible online.

Correspondence to: Spyridon Davakis, MD, General Surgery Registrar, Upper Gastrointestinal and General Surgery Unit, Laiko General Hospital, National and Kapodistrian Unversity of Athens, 17 Agiou Thoma Str., 11527, Athens, Greece. Tel: +30 6973762451, e-mail: spdavakis@gmail.com

Key Words: Esophageal bypass, squamous cell carcinoma, esophagobrochial fistula, 3D laparoscopy.
(1). The most common presenting symptom of esophageal cancer is dysphagia, leading to severe malnutrition and reduced quality of life (2). Esophagectomy is the mainstay in curative treatment for local and loco-regional disease (3). However, definitive chemoradiotherapy (CRT) is provided as palliative treatment to prolong the survival and relieve the symptoms in patients with advanced disease (3). Definitive CRT in esophageal squamous cell carcinoma can be used with a curative intent. Long-term results have revealed similar overall survival for T1bN0M0 esophageal cancer patients treated with CRT or esophagectomy alone, while local recurrence rate was higher in the CRT group (4).

In locally advanced esophageal tumors, disease progression often involves tumor invasion into adjacent organs such as the trachea or bronchus, partly due to lack of serosal layer (5). The prognosis of T4b esophageal cancer is generally poor; however, 5-year survival of 5\% to $10 \%$ is estimated after definitive CRT (5).

The stomach has been used extensively as an excellent conduit for reconstruction in esophageal bypass (6), but its use as a bridge to definitive treatment has been reported only in few studies.

\section{Case Report}

We present the case of a 49-year-old female patient, with a medical history of esophageal achalasia for more than 10 years. She complained of fever due to microaspirations and mild respiratory distress for the past fifteen days accompanied with progressive dysphagia, retrosternal pain and extensive weight loss. Full blood count revealed leukocytosis $\left(14.300\right.$ per $\mathrm{mm}^{3}$ ) with right shift (Neut=79\%); the rest of laboratory tests were within normal limits.

Clinical examination revealed severe cachexia with sarcopenia and decreased air entry on the right chest. Chest $\mathrm{X}$-ray showed right apical pleural thickening with fibroatelectatic changes in the right middle and lower 


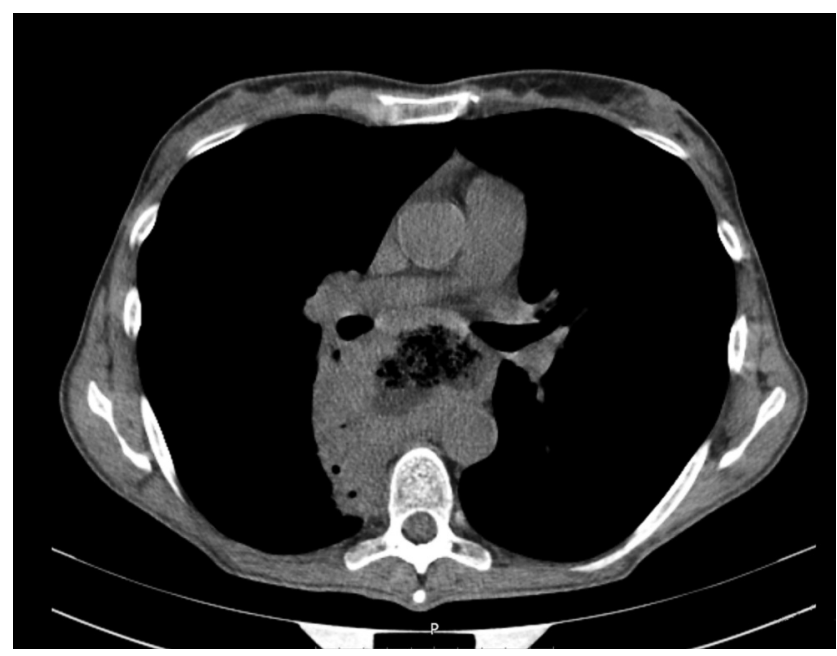

Figure 1. Computed tomography of the chest showing a mid-esophageal tumor with invasion of $2^{\text {nd }}$ class bronchi beneath the right main bronchi.

lobe. Contrast-enhanced computed tomography (CT) scan of the chest and abdomen revealed the presence of an extensive and unresectable mid-esophageal tumor with an esophagobronchial fistula at the level of the right secondary bronchus (Figures 1,2), alongside lymphadenopathy in the abdomen and chest. Moreover, there was evidence of bronchiectatic changes in both the right upper and middle lobes with subpleural fibroatelectatic changes in the posterior segment of the right upper lobe, most likely due to recurrent aspirations. Upper gastrointestinal endoscopy revealed megaesophagus with tight esophago-gastric junction related to achalasia and a circumferential inflammatory lesion from 20 to $25 \mathrm{~cm}$ from the incisors with the presence of esophagobronchial fistula. Biopsies of the esophagus lesion revealed a moderately differentiated squamous cell carcinoma.

Based on these findings, the patient was offered cervical esophagostomy; however, she declined due to poor quality of life that it offers. As a result, the only possible surgical treatment was esophageal bypass. The patient underwent 3Dlaparoscopic-assisted bypass surgery as a bridge to definitive CRT with possible curative intent; due to respiratory distress, the process was converted to open.

The patient was placed to a split-leg table position and steep reverse Trendelenburg was used. Laparoscopy revealed huge right and left liver lobes, probably related to long-term parenteral nutrition that the patient was receiving. Due to the latter, an adjustment of trocar placement with caudal shift was performed (Figure 3). Mobilization of the stomach greater curve, with partition of the gastrocolic and gastrosplenic ligaments, including ligation of the left gastroepiploic and short gastric vessels, 3-4 cm outside the

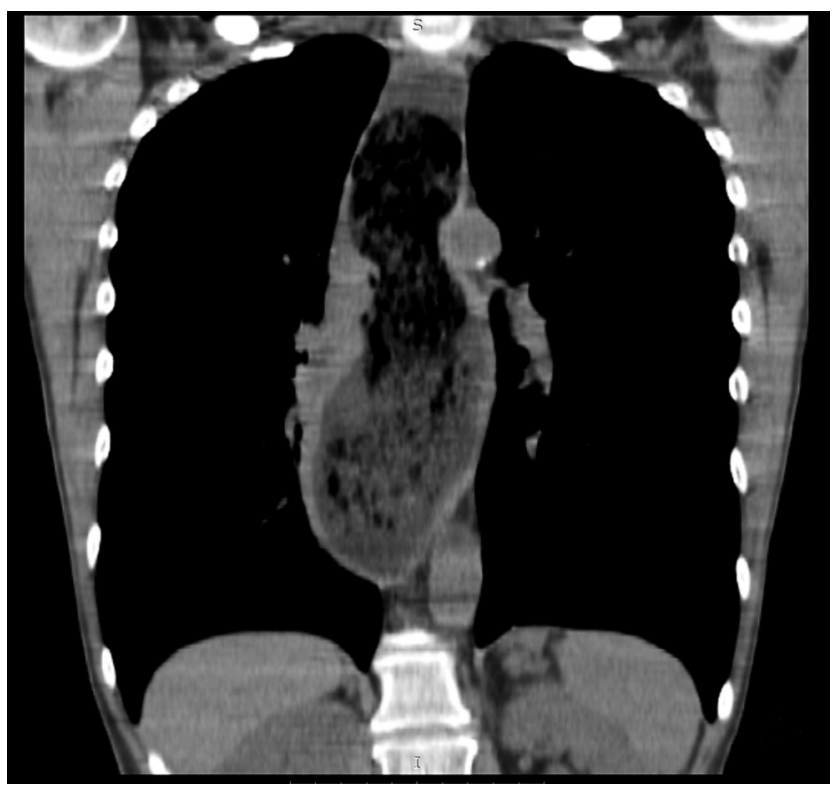

Figure 2. Frontal view of computed tomography showing the esophageal mass.

vascular arcade was performed. The greater omentum was divided and the right gastroepiploic vessels, right gastric vessels, and left gastric vessels were all preserved. The right liver lobe was mobilized to gain access to the gastric cardia and subxiphoid space, by dissecting the right triangular and coronary ligaments. A retrosternal canal from the xiphisternum to the manubrium sterni was then formed under direct 3D laparoscopic vision. The patient presented mild tachycardia with signs of hypercapnia and was unable to tolerate laparoscopy. Due to respiratory distress, the procedure was converted to open with a midline laparotomy.

Following that, the V-shaped division of the stomach with the long gastric tube was performed. Stomach partition was performed using a $21 \mathrm{~mm}$ circular stapler, which was inserted $2 \mathrm{~cm}$ above the pylorus and $5 \mathrm{~mm}$ medial to the lesser curve, anastomosing the anterior to the posterior gastric wall, in order to allow mucus from the about-to-be-formed esophageal blind end to drain (Figure 4). Utilizing this gastric opening, a V-shaped gastric partition with a 2- to 3-cm-wide gastric conduit was constructed up to the level of gastric cardia (Figure 5), using the iDrive ${ }^{\mathrm{TM}}$ ultra powered stapling system (Medtronic, Minneapolis, MN, USA) with purple staple cartridges. Simultaneously, an incision was made on the left side of the neck. The enlarged cervical esophagus was dissected, taking care not to injure the recurrent laryngeal nerves, and was divided above the sternal notch using the iDrive $^{\mathrm{TM}}$ ultra powered stapling system with purple staple cartilage. The gastric pull-up was brought behind the mobilized left liver lobe up to the left neck through the previously formed retrostrernal canal (Figure 6); then, it was 


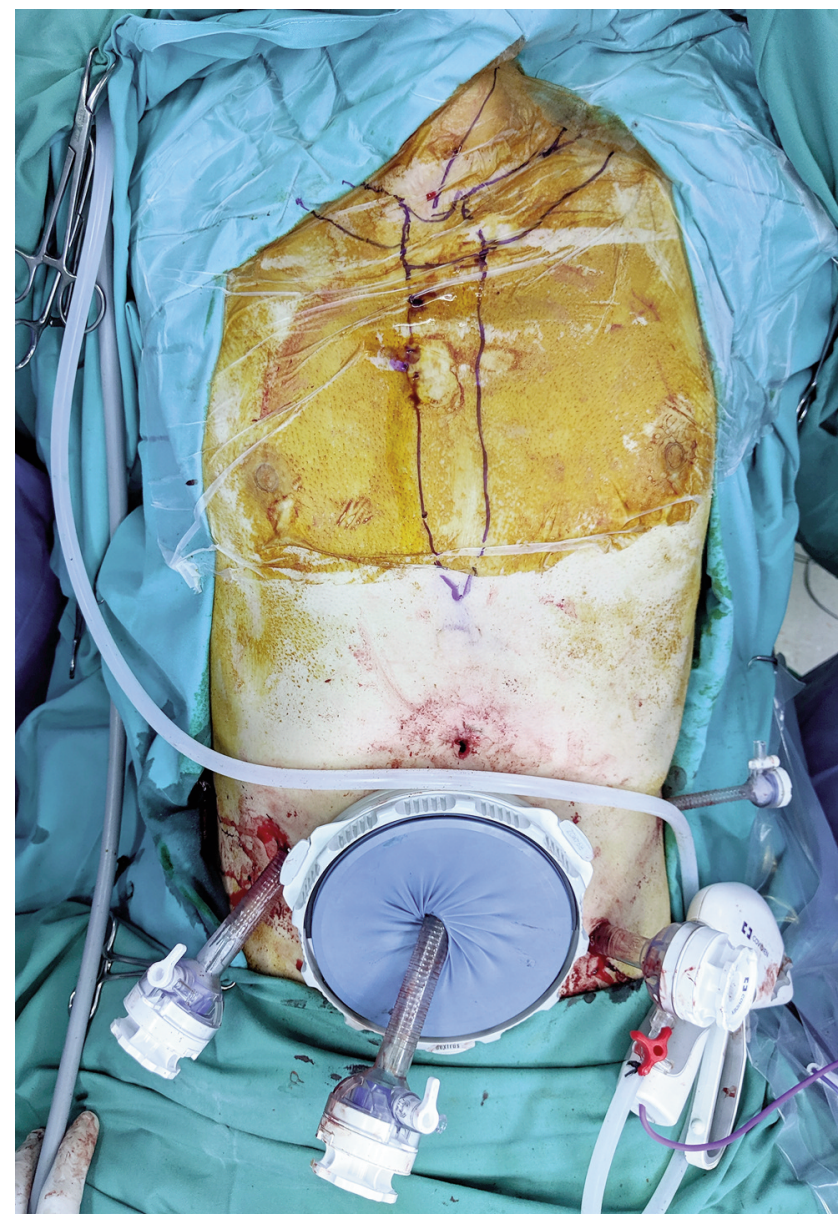

Figure 3. Abdominal trocar placement alongside neck preparation.

anastomosed to the cervical esophagus in an end-to-side manner in a single layer, using PDS 4/0 (Ethicon, Cornelia, GA, USA) interrupted Gambee sutures. In order to allow easy passage of the gastric conduit into the neck through a tight thoracic inlet, a partial resection of the sternal head of the left clavicle and the supero-posterior aspect of the manubrium sterni was carried out. A penrose drain was placed around the esophageal stump in the neck. A feeding jejunostomy was placed. Operation time was $220 \mathrm{~min}$, with blood loss less than $250 \mathrm{ml}$. No blood transfusion was needed intra-operatively (pre-operative $\mathrm{HGb}$ was $10.5 \mathrm{mg} / \mathrm{dl}$ ). The patient was transferred to intensive care unit (ICU).

Due to general anesthesia and an intraoperative edema caused by the endotracheal tube, a postoperative respiratory disequilibrium was observed, that did not allow extubation for 15 post-operative days. She was then returned to the clinic, and after barium swallow test (on the $20^{\text {th }}$ postoperative day), oral diet was commenced. Leakage from the cervical anastomosis was observed two days later, which was

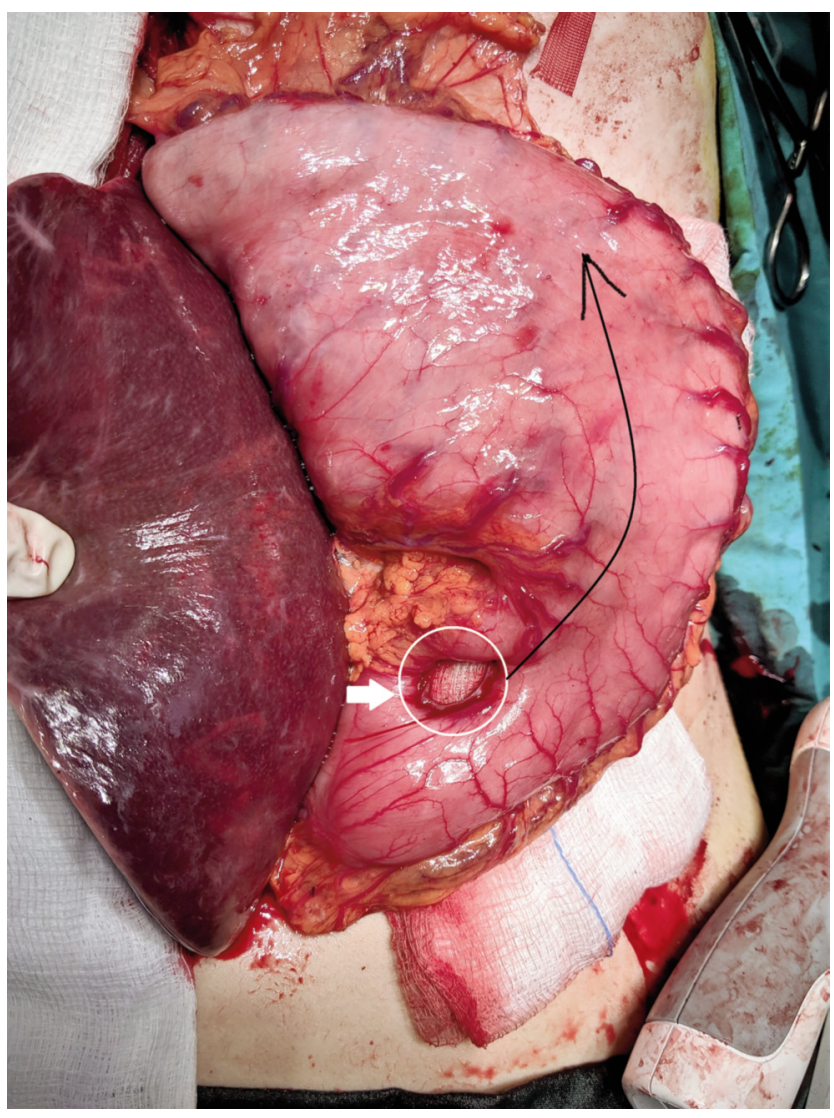

Figure 4. Stomach partition formed with a 21-mm circular stapler. The black arrow indicates the resection line along the stomach. The white arrow indicates the initial partition of the stomach with circular stapler.

managed conservatively, with nil per os and parenteral nutrition for 2 weeks. One month later, the patient underwent 3 cycles of radiotherapy and after closure of the anastomotic leak, 3 cycles of CRT were administrated. Over the following 8 months, tumor regression was observed (Figure 7). For now, ten months after surgery, the patient is in a good overall clinical status, free of respiratory distress symptoms, with acceptable oral food intake.

\section{Discussion}

Squamous cell esophageal cancer can present with esophagobronchial/trachoesophageal fistula in $5 \%$ to $15 \%$ of patients, accompanied by severe or complete dysphagia and respiratory distress (7). Esophagobronchial fistulas lead to severe morbidity and mortality, with life threatening respiratory sepsis, due to gastrointestinal contamination of the tracheobronchial tree (8); if left untreated, median survival is estimated to be less than 4 weeks (9). Furthermore, esophageal 


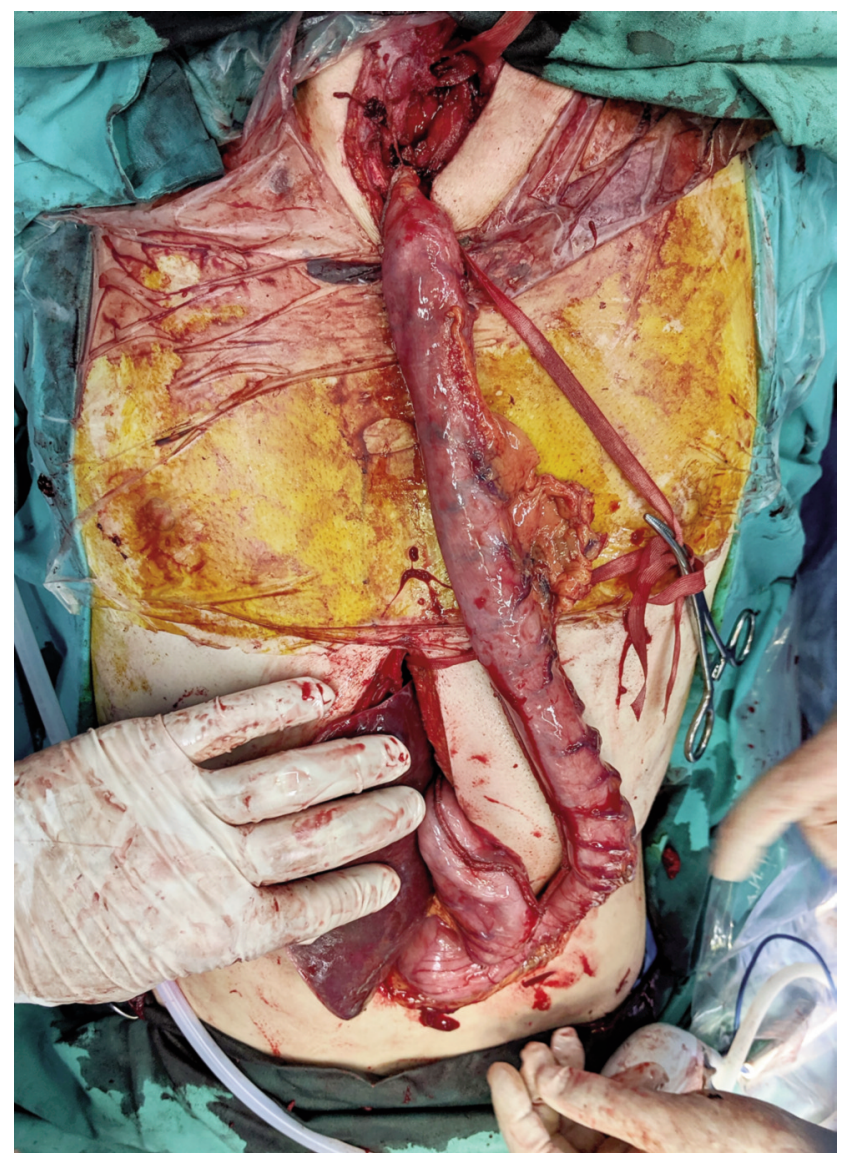

Figure 5. Formed gastric conduit.

cancer patients with esophagobronchial fistula are confronted with the inability to take in food orally. As a result, their nutritional status deteriorates rapidly with detrimental consequences due to severe sarcopenia (10).

Treatment options for such fistulas include tracheal, esophageal, or both (double) stenting (11), as well as surgical bypass with gastric or colon conduit (12). Self-expandable metallic stent utilization is a safe method of palliating severe dysphagia and fistulas (11). Stenting can offer a less invasive approach, mostly in debilitated patients and is generally preferred. In the present case, pre-operative stenting of the airway or esophagus was not an option, due to inability to stent the secondary bronchus or megaesophagus, respectively.

Surgical bypass operation can be performed in younger patients or in patients with relatively good performance status, for whom stenting is not an option (6). Peri-operative mortality rate is high for the radical operation, as has been recently reported (13). There is an excellent alternative described by Kirschner (14), known as Kirschner's operation, which includes a retrosternal gastric bypass with drainage or ligature of the lower esophagus. Although the reported palliation is

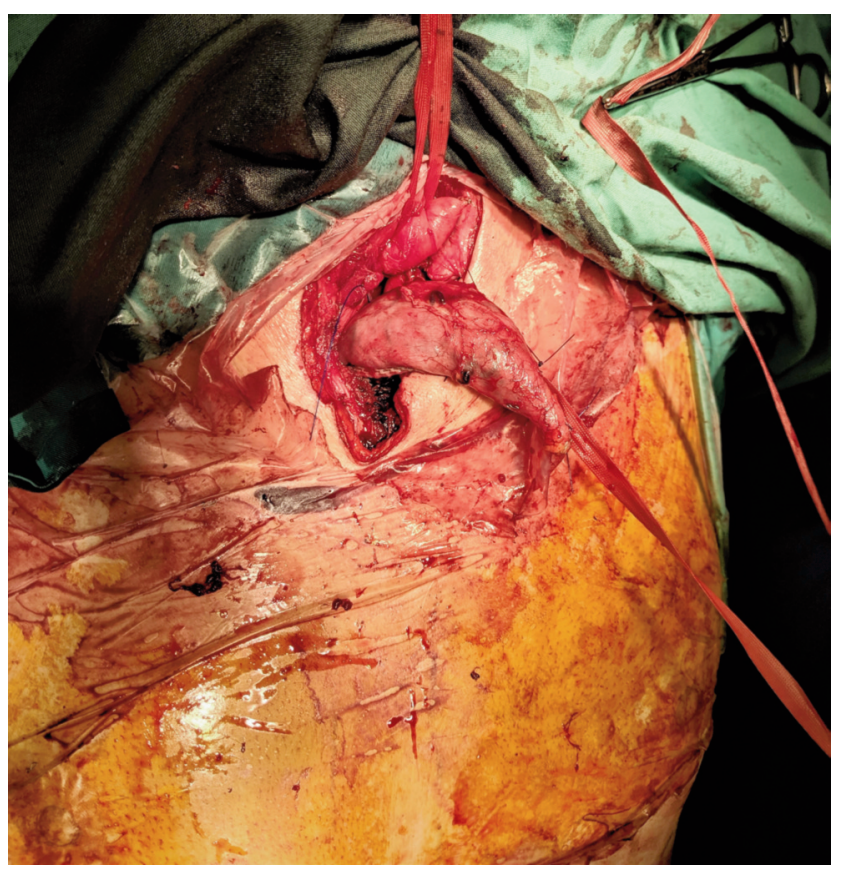

Figure 6. Divided cervical esophagus and pulled-up gastric conduit.

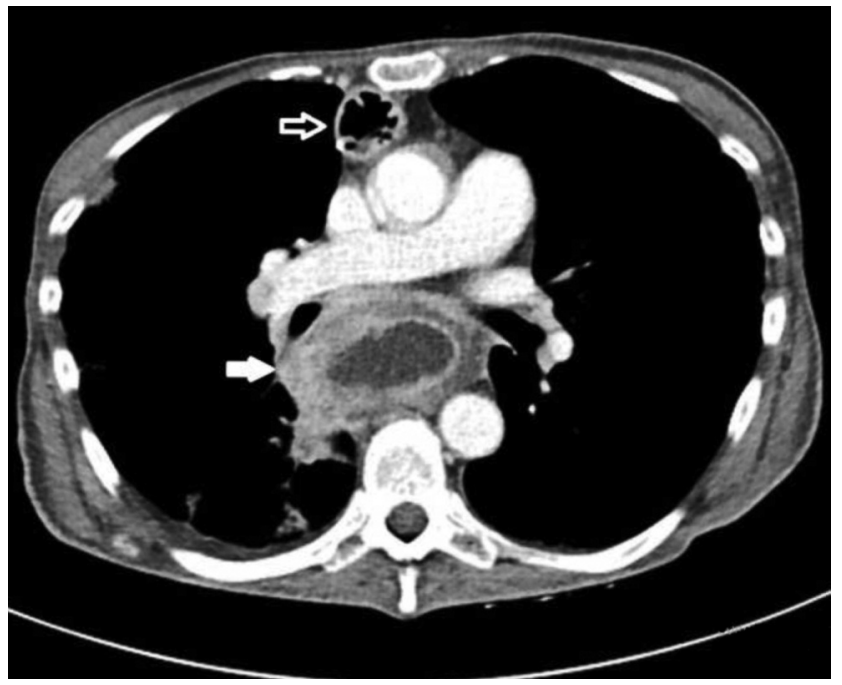

Figure 7. Six months follow-up computed tomography scan shows tumor regression (white arrow) and the retrosternal gastric tube (white lined black arrow).

good, mortality rate exceeds $20 \%$ (15-17). According to Kirschner's operation, associating gastric bypass with ligature of the lower esophagus offers the advantage of postoperative radiotherapy, while protecting the bypass from tumoral invasion (14). This procedure enables control of the respiratory infection and adequate nourishment of the patients (14). 
Retrosternal gastric bypass can be performed in various clinical cases, both for malignant and benign esophageal entities (6). It can provide relief from aspiration symptoms through separation of the respiratory and alimentary tracts (12). Additionally, retrosternal gastric bypass has been reported with excellent results in cases with high risk of developing locoregional recurrence after esophagectomy for prevention of later conduit obstruction (17). Other than retrosternal route, the newly formed conduit can pass through the subcutaneous space. However, this technique has several disadvantages, as it is the longest route, while it has been associated with higher risk of tube trauma and kinking (6). For these reasons, the subcutaneous route is reserved as the last option for patients with previous mediastinal surgery and pleural infection or mediastinal fibrosis (18).

Small bowel or colon conduits can also be used for surgical bypass; the colon or the jejunum are utilized as conduits in patients with a history of previous gastric surgery. Although palliative coloplasty is mostly performed, others prefer the better congruence obtained with the right ileocolon accompanied with removal of the first rib and the clavicle (19). When jejunum or ileum is used as conduit, cervical supercharging is needed to establish adequate blood flow and avoid vein congestion (20). To reduce the risk of anastomotic cervical fistula, and the risk of excessive pressure in the formed retrosternal conduit, partial exeresis of the clavicle and manubrium sterni has been proposed (21).

Javed et al. were the first to describe a laparoscopic technique for bypass in patients with corrosive esophageal strictures, using either a gastric or a colonic conduit (22). The authors reported on safety, feasibility, and effectiveness of this technique, alongside the established advantages of minimally-invasive techniques, such as faster recovery, fewer respiratory complications, and minimal postoperative pain. In addition, laparoscopy can provide direct visualization of the substernal dissection (23). However, despite all the advantages of minimally-invasive laparoscopic approach, advanced tumor stage and compromised performance status are associated with higher rates of conversion to open procedure (laparotomy), as in our case (24).

3D-assisted laparoscopy, as was initially utilized in our case, has been shown to provide all the advantages of minimally-invasive approach, amplified with better depth perception and detailed optics, and appears to be superior comparing to 2D-laparoscopy procedures (25).

In the literature, there are several reports of esophageal bypass, with the vast majority reporting a palliative procedure $(6,12,22,23)$. However, in the present case, the esophageal bypass was performed with curative intent, provided that definitive CRT could be administered. The rationale behind this procedure was that it would isolate the aerodigestive fistula and allow the patient to have oral nutrition. Thus, the patient would be able to tolerate and complete the following CRT cycles. In addition, by this surgical technique the use of esophageal drainage (via a transthoracic or transabdominal esophagostomy tube) and consequent poor quality of life are avoided, by allowing native drainage of the esophageal stump through the non-divided gastric lesser curve. Despite the fact that it is a high risk and far-fetched treatment approach, multimodality treatment with CRT and surgery, as described in our paper, in this order is the only combination that can potentially provide curative treatment of advance squamous esophageal cancer complicated with esophagobronchial/tracheoesophageal fistula. Any other treatment would be with palliative intent and would have compromised the radiotherapy field and result.

Laparoscopic-assisted esophageal bypass (with nondivided stomach and without the need of esophageal drainage) with a gastric conduit for patients with advanced mid-esophageal fistulating cancer is technically demanding but feasible. It can be part of a therapeutic equation with curative intent in fit patients. In the extremely severe situation caused by esophagobrochial/tracheoesophageal fistula, inevitably leading to severe morbidity and mortality, surgical bypass operations can eliminate respiratory contamination while improving the patient's quality of life by allowing normal food intake.

\section{Conflicts of Interest}

The Authors have no potential conflict of interest.

\section{Authors' Contributions}

Spyridon Davakis: study conception, drafting of manuscript and analysis and interpretation of data; Athanasios Syllaios: drafting of manuscript and analysis and interpretation of data; Efstratia Mpaili: analysis and interpretation of data; Theodoros Liakakos: study conception and design; Alexandros Charalabopoulos: study conception and design, acquisition of data and critical revision of manuscript.

\section{Informed Consent}

Informed consent was obtained from the patient included in the current manuscript.

\section{References}

1 Sdralis E, Tzaferai A, Davakis S, Syllaios A, Kordzadeh A, Lorenzi B and Charalabopoulos A: Reinforcement of intrathoracic oesophago-gastric anastomosis with fibrin sealant (Tisseel ${ }^{\circledR}$ ) in oesophagectomy for cancer: A prospective comparative study. Am J Surg 219(1): 123-128, 2020. PMID: 31235074. DOI: 10.1016/j.amjsurg.2019.06.013

2 Siosaki MD, Lacerda CF, Bertulucci PA, da Costa Filho JO and de Oliveira AT: Bypass laparoscopic procedure for palliation of esophageal cancer. J Surg Case Rep 2013(3): pii: rjt017, 2013. PMID: 24964427. DOI: 10.1093/jscr/rjt017 
3 Kitagawa Y, Uno T, Oyama T, Kato K, Kato H, Kawakubo H, Kawamura O, Kusano M, Kuwano H, Takeuchi H, Toh Y, Doki Y, Naomoto Y, Nemoto K, Booka E, Matsubara H, Miyazaki T, Muto M, Yanagisawa A and Yoshida M: Esophageal cancer practice guidelines 2017 edited by the Japan esophageal society: part 2. Esophagus 16(1): 25-43, 2019. PMID: 30171414. DOI: 10.1007/s 10388-018-0642-8

4 Motoori M, Yano M, Ishihara R, Yamamoto S, Kawaguchi Y, Tanaka K, Kishi K, Miyashiro I, Fujiwara Y, Shingai T, Noura $\mathrm{S}$, Ohue $\mathrm{M}$, Ohigashi $\mathrm{H}$, Nakamura $\mathrm{S}$ and Ishikawa $\mathrm{O}$ : Comparison between radical esophagectomy and definitive chemoradiotherapy in patients with clinical T1bN0M0 esophageal cancer. Ann Surg Oncol 19(7): 2135-2141, 2012. PMID: 22302264. DOI: 10.1245/s 10434-012-2231-8

5 Diamantis G, Scarpa M, Bocus P, Realdon S, Castoro C, Ancona E and Battaglia G: Quality of life in patients with esophageal stenting for the palliation of malignant dysphagia. World $\mathrm{J}$ Gastroenterol 17(2): 144-150, 2011. PMID: 21245986. DOI: 10.3748/wjg.v17.i2.144

6 Meunier B, Spiliopoulos Y, Stasik C, Lakéhal M, Malledant Y and Launois B: Retrosternal bypass operation for unresectable squamous cell cancer of the esophagus. Ann Thorac Surg 62(2): 373-377, 1996. PMID: 8694594.

7 Kimura M, Ishiguro H, Tanaka T and Takeyama H: Advanced esophageal cancer with tracheobronchial fistula successfully treated by esophageal bypass surgery. Int J Surg Case Rep 9: 115-118, 2015. PMID: 25765740. DOI: 10.1016/j.ijscr. 2015.02.053

8 Ohsawa M, Hamai Y, Ibuki Y, Emi M, Miyata Y and Okada M: Long-term esophageal cancer survivor treated by bypass for esophagobronchial fistula after chemoradiotherapy: A case report. Anticancer Res 39(8): 4399-4403, 2019. PMID: 31366536. DOI: 10.21873/anticanres.13610

9 Dobrucali A and Caglar E: Palliation of malignant esophageal obstruction and fistulas with self expandable metallic stents. World J Gastroenterol 16(45): 5739-5745, 2010. PMID: 21128325. DOI: $10.3748 /$ wjg.v16.i45.5739

10 Reim D and Friess H: Feeding challenges in patients with esophageal and gastroesophageal cancers. Gastrointest Tumors 2(4): 166-177, 2016. PMID: 27403411. DOI: 10.1159/ 000442907

11 Shin JH, Kim JH and Song HY: Interventional management of esophagorespiratory fistula. Korean J Radiol 11(2): 133-140, 2010. PMID: 20191059. DOI: 10.3348/kjr.2010.11.2.133

12 Hihara J, Hamai Y, Emi M, Aoki Y, Taomoto J, Miyata Y and Okada M: Esophageal bypass operation prior to definitive chemoradiotherapy in advanced esophageal cancer with tracheobronchial invasion. Ann Thorac Surg 97(1): 290-295, 2014. PMID: 24200399. DOI: 10.1016/j.athoracsur.2013.08.060

13 Nakajima Y, Kawada K, Tokairin Y, Miyawaki Y, Okada T, Miyake S and Kawano T: Retrospective analyses of esophageal bypass surgery for patients with esophagorespiratory fistulas caused by esophageal carcinomas. World J Surg 40(5): 1158-1164, 2016. PMID: 26732670. DOI: 10.1007/s00268-015-3391-z.
14 Ong GB: The Kirschner operation. A forgotten procedure. Br J Surg 60(3): 221-227, 1973. PMID: 4632679. DOI: 10.1002/bjs. 1800600315

15 Mannell A, Becker PJ and Nissenkorn M: Bypass surgery for unresectable oesophageal cancer: early and late results in 124 cases. Br J Surg 75(3): 283-286, 1988. PMID: 2450615. DOI: $10.1002 /$ bjs. 1800750332

16 Conlan AA, Nicolaou N, Hammond CA, Pool R, De Nobrega C and Mistry BD: Retrosternal gastric bypass for inoperable esophageal cancer: a report of 71 patients. Ann Thorac Surg 36(4): 396-401, 1983. PMID: 6194765. DOI: 10.1016/s00034975(10)60476-6

17 Whooley BP, Law S, Murthy SC, Alexandrou A, Chu KM and Wong J: The Kirschner operation in unresectable esophageal cancer: current application. Arch Surg 137: 1228-1232, 2002. PMID: 12413307. DOI: 10.1001/archsurg.137.11.1228

18 Javed A and Agarwal AK: Laparoscopic retrosternal bypass for corrosive stricture of the esophagus. Surg Endosc 26(11): 33443349, 2012. PMID: 22552862. DOI: 10.1007/s00464-012-2307-3

19 Javed A and Agarwal AK: Total laparoscopic esophageal bypass using a colonic conduit for corrosive-induced esophageal stricture. Surg Endosc 27(10): 3726-3732, 2013. PMID: 23636519. DOI: $10.1007 / \mathrm{s} 00464-013-2956-\mathrm{x}$

20 Halpern AL, Friedman C, Torphy RJ, Al-Musawi MH, Mitchell JD, Scott CD, Meguid RA, McCarter MD, Weyant MJ and Gleisner AL: Conversion to open surgery during minimally invasive esophagectomy portends worse short-term outcomes: an analysis of the National Cancer Database. Surg Endosc, 2019. PMID: 31591657. DOI: 10.1007/s00464-019-07124-y

21 Hanagiri T, Morita M, Shigematsu Y, Takenaka M, Oka S, Nagata Y, Shimokawa H, Uramoto H and Tanaka F: Esophageal bypass using a gastric tube for a malignant tracheoesophageal/ bronchoesophageal fistula: a report of 4 cases. Int Surg 96(3): 189-193, 2011. PMID: 22216695. DOI: 10.9738/cc38.1

22 Orringer MB and Sloan H: Substernal gastric bypass of the excluded thoracic esophagus for palliation of esophageal carcinoma. J Thorac Cardiovasc Surg 70(5): 836-851, 1975. PMID: 52764

23 Bakshi A, Sugarbaker DJ and Burt BM: Alternative conduits for esophageal replacement. Ann Cardiothorac Surg 6(2): 137-143, 2017. PMID: 28447002. DOI: 10.21037/acs.2017.03.07

24 Moore JM, Hooker CM, Molena D, Mungo B, Brock MV, Battafarano RJ and Yang SC: Complex esophageal reconstruction procedures have acceptable outcomes compared with routine esophagectomy. Ann Thorac Surg 102(1): 215-222, 2016. PMID: 27217296. DOI: 10.1016/j.athoracsur.2016.02.039

25 Sinha RY, Raje SR and Rao GA: Three-dimensional laparoscopy: Principles and practice. J Minim Access Surg 13(3):165-169, 2017. PMID: 27143695. DOI: 10.4103/0972-9941.181761

Received January 28, 2020

Revised April 8, 2020

Accepted April 17, 2020 